\title{
Psoriatic arthritis in patients with psoriasis: evaluation of clinical and epidemiological features in 133 patients followed at the University Hospital of Brasília
}

\author{
Artrite psoriásica em pacientes com psoríase: avaliação de características clínicas e \\ epidemiológicas em 133 pacientes atendidos no Hospital Universitário de Brasília
}

\author{
Jamille Nascimento Carneiro \\ Gladys Aires Martins ${ }^{3}$
}

\author{
Ana Patrícia de Paula ${ }^{2}$
}

\begin{abstract}
BACKGROUND: Psoriatic arthritis is an inflammatory arthritis associated with psoriasis. Its prevalence in patients with psoriasis varies from 7 to $42 \%$ but its exact prevalence is unknown.

OBjectives: Considering the lack of national data related to its diagnosis in patients with psoriasis, this study aims to describe the clinical, laboratorial and radiological manifestations of psoriatic arthritis in these patients.

Methods: We evaluated 133 patients with psoriasis, treated as outpatients. These patients were asked to fill in the forms with data about the disease and were submitted to a clinical evaluation by a dermatologist and a rheumatologist. Suspected cases of arthritis were referred for further investigation and were classified according to presence or absence of psoriatic arthritis according to CASPAR criteria.

ResulTs: The number of patients with psoriatic arthritis was 47 (35\%), 17 of them were new cases. There was no difference between the groups regarding the type of psoriasis, nail involvement, presence of scalp lesions and psoriatic arthritis. Patients with psoriatic arthritis had more enthesitis and dactylitis (46.7\%) than those without arthritis.

Conclusions: Despite the high prevalence of arthritis found, we know that results from epidemiological studies are variable, which limits their use and interpretation. We conclude that more studies are needed to draw a profile of rheumatic manifestations in our population of psoriasis patients.
\end{abstract}

Keywords: Arthritis, psoriatic; Brazil; Psoriasis

Resumo: Fundamentos: A artrite psoriásica é uma artrite inflamatória associada à psoríase. Sua prevalência nos pacientes com psoríase de 7 a $42 \%$ mas sua exata prevalência ainda é desconhecida.

OBJetivos: Considerando a escassez de dados nacionais relacionados ao seu diagnóstico em pacientes com psoríase o presente estudo visa descrever o quadro clínico, laboratorial e radiológico da doença nesses pacientes.

MÉTodos: Foram avaliados 133 pacientes com diagnóstico de psoríase acompanhados no ambulatório de Psoríase: Esses pacientes foram submetidos ao preenchimento de fichas com dados sobre sua doença e depois a uma avaliação clínica pelo dermatologista e reumatologista. Casos suspeitos de artrite foram encaminhados para realização de investigação complementar e foram classificados quanto à presença ou não de artrite psoriásica segundo critérios de CASPAR.

Resultados: O número de pacientes com Artrite Psoriásica foi de 47 pacientes (35\% ) sendo 17 desses casos novos. Não houve diferença entre os grupos quanto ao tipo de psoríase, envolvimento ungueal e de couro cabeludo e presença de artrite psoriásica. Pacientes com artrite psoriásica apresentaram mais entesites e dactilite $(46,7 \%)$ do que os sem artrite.

CONCLUSÕES: Apesar da alta prevalência de artrite encontrada como sabemos que resultados de estudos epidemiológicos são variáveis levando a limitação em seu uso e interpretação concluímos que mais estudos são necessários para se traçar um perfil de manifestações reumatológicas em nossa população de pacientes psoriásicos.

Palavras-chave: Artrite psoriásica; Brasil; Psoríase

Received on 07.08.2011

Approved by the Advisory Board and accepted for publication on 20.11.2011.

* Work performed at the Psoriasis Outpatients Clinic of the Hospital Universitário de Brasília - Universidade de Brasília (HUB-UnB) - Brasília (DF), Brazil.

Conflict of interest: None

Financial funding: None

Medical Residency in Rheumatology by the Universidade de Brasília (UnB). Rheumatologist of the Health Secretariat of the Distrito Federal. Rheumatologist at the Centro de Reumatologia do Distrito Federal - Brasília (DF), Brazil.

$\mathrm{PhD}$ in Health Sciences with concentration in Rheumatology by the Universidade Federal de São Paulo (UNIFESP) - Orienting Teacher of the Post-Graduation program of the Faculdade de Ciências da Saúde of the Hospital Universitário de Brasília - Universidade de Brasília (HUB-UnB). Rheumatologist at the Health Secretariat of the Distrito Federal - Brasília (DF), Brazil.

Specialist in Dermatology by the Brazilian Society of Dermatology (Sociedade Brasileira de Dermatologia). Master in Dermatology by the Universidade Federal de Minas Gerais (UFMG) - Dermatologist of the Hospital Universitário de Brasília - Universidade de Brasília (HUB-UnB) - Brasília (DF), Brazil. 


\section{INTRODUCTION}

Rheumatic manifestations are ten to fifteen times more common in patients with psoriasis than in the general population. Psoriasis patients even show a percentage greater than $40 \%$ of inflammatory joint manifestations. ${ }^{1}$ Between $5 \%$ and $40 \%$ of the patients who suffer from psoriasis will develop psoriatic arthritis, but not every patient with psoriasis will present with psoriatic arthritis and not any joint manifestation is psoriatic arthritis. Rheumatoid arthritis, osteoarthritis and joint pain are common in the general population and in patients with psoriasis. ${ }^{2}$ Nevertheless, it is recommended that specific enquiry about joint disease should be sought in all patients with psoriasis.

While the prevalence of arthritis in the general population is estimated at $2-3 \%$, in patients with psoriasis it varies from 7 to $42 \%$. Moll and Wright concluded from a review of epidemiological studies and scientifically support the concept that psoriatic arthritis is a single entity, with clinical, serological and radiological characteristics, and provided the earliest diagnostic criteria for psoriatic arthritis. ${ }^{4-6}$ Nowadays it is generally agreed that while psoriatic arthritis can be classified among spondyloarthropathies, a family of disorders sharing common features like inflammatory arthritis, axial involvement, enthesopathy, absence of rheumatoid factor and association with HLA. ${ }^{5,6}$

There is no general agreement in the literature regarding the prevalence of psoriatic arthritis. The estimate of prevalence has been difficult because of the paucity of widely accepted classification or diagnostic criteria and the difficulty of most experts in making a correct diagnosis. ${ }^{5}$

There are still some difficulties for the diagnosis of psoriatic arthritis, so several classification criteria have been proposed. ${ }^{7}$ The CASPAR criteria for classification are comparable to others but have shown better sensitivity, facilitating the recruitment of patients in studies of psoriatic arthritis. ${ }^{8}$

The typical clinical features of psoriatic arthritis include distal joint involvement which occurs in more than half of patients, but its isolated occurrence is rare. Oligoarticular involvement is seen and about half of patients have the spondyloarthropathy form, which is usually less symptomatic when compared to ankylosing spondylitis. Half of the patients also have dactylitis and enthesitis. ${ }^{4}$ More recently, three joint patterns were identified: oligoarticular (£ 4 affected joints) or polyarticular ( $\geq 5$ joints affected) or peripheral pattern and axial pattern with or without associated peripheral arthritis. ${ }^{9}$

Considering the lack of national data related to the diagnosis of psoriatic arthritis in patients with psoriasis, this study aims to describe the clinical, laboratorial and radiological features in 133 psoriatic patients with and without psoriatic arthritis from the outpatients' clinic of dermatology at the Brasília University Hospital.

\section{PATIENTS AND METHODS \\ Sample}

We carried out a cross-sectional study in 133 patients with psoriasis who visited the Outpatient's Department of Dermatology at University Hospital of Brasilia, between November 2009 and December 2010. Convenience sampling was done and our sample represented $33 \%$ of all the patients already enrolled in the psoriasis outpatients' clinic.

The study was approved by the local ethics committee according to Brazilian Standards for Research involving Human Subjects and the Helsink Declaration. We recruited consecutively and included patients diagnosed with psoriasis, according to clinical criteria by an experienced dermatologist and/or biopsy. All patients who agreed to participate in the study signed the informed consent form.

\section{METHODS}

Psoriasis's clinical evaluation was performed by a dermatologist. The study followed the routine of the dermatological service with filling of the specific form where the first skin symptoms, the year of diagnosis, the form of the disease, nail involvement, scalp involvement, smoking, alcohol consumption, diseases history, previous treatments and family history of psoriasis were recorded. The form was sent to the rheumatologist to collect information for the study.

All patients who agreed to participate in this study were evaluated by a rheumatologist on the same day by the protocol for evaluation of joint manifestations, which included the presence of pain / joint swelling, dactylitis, enthesitis, neck pain, back pain, previous diagnosis of psoriatic arthritis or other forms of arthritis, date of diagnosis and type of joint involvement.

The rheumatologist was the first author of this study and evaluated all patients according to the recommendations by GRAPPA (Group for Research and Assessment of Psoriasis and Psoriatic Arthritis) and the OMERACT (Outcome Measures in Rheumatology Clinical Trials). ${ }^{10}$ Thus the axial and peripheral skeletons were clinically evaluated. ${ }^{11}$

The suspected cases of psoriatic arthritis were sent to laboratorial and radiological research. The diagnosis of psoriatic arthritis was made according to the CASPAR criteria. ${ }^{12}$

\section{Statistical Analysis}

We conducted the Kolmogorov-Smirnov test to 
verify the normality of the sample and then used the $\mathrm{X}$ 2 test, Fischer exact test, Student T and Mann-Whitney tests. Statistical analyses were undertaken by SPSS ${ }^{\circledR}$ version 15.0 (SPSS Inc., Chicago, IL, USA). A p-value less than 0.05 was considered statistically significant $(\mathrm{p}<0.05)$.

\section{RESULTS}

Considering the prevalence of $25 \%$ of psoriatic arthritis in patients with psoriasis the power of the sample was $60 \%$.

We evaluated 62 men and 71 women diagnosed with psoriasis. The average age of the sample was 47.5 $( \pm 13.4)$ years, ranging between 17 and 82 years. Seven patients reported current alcohol use and 12 were smokers. Eighteen patients had a high blood pressure (13.5\%) and 10 (7.5\%) had a diagnosis of diabetes mellitus. Only five patients reported a family history of psoriasis and there was no information in this regard in 97 of the dermatological reports.

Chart 1 shows the sex distribution by type of psoriasis. There was no information on the classification form of psoriasis from 25 patients.

It is noteworthy that all five patients with the palmoplantar form were women and two with the erythrodermic form were male.

Thirty-nine patients (39\%) had nail involvement, according to the dermatologist. However, in 50 (38\%) patients, the dermatologist did not report whether there were nail changes.

Regarding the presence of scalp involvement, lesions were reported in 66 (49.6\%) patients, but there was no information on injuries to the scalp in 49 $(36.8 \%)$ patients.

As for the complaints of the musculoskeletal system, one hundred and one patients $(80.5 \%)$ had joint pain, 91 (68.4\%) reported back pain and 67 (50.4\%) neck pain.

The presence of enthesitis was found in 17 (12.8\%) patients and the diagnosis of dactylitis was made in 27 patients $(20.3 \%)$ at the time of the assessment by the rheumatologist. Regarding the use of drugs by the patients, it was observed that $30(22.6 \%)$ patients used anti-inflammatory drugs, 22 (16.5\%)

Chart 1: Classification of psoriasis by sex

\begin{tabular}{|lll|}
\hline Type of psoriasis & Male & Female \\
Vulgar & 41 & 48 \\
Guttata & 2 & 3 \\
Palmoplantar & 0 & 5 \\
Pustular & 2 & 3 \\
Erythrodermic & 2 & 0 \\
Nail psoriasis & 1 & 1 \\
\hline
\end{tabular}

patients used disease-modifying drugs and the use of biological drugs was reported by 08 (6\%) patients.

Previous diagnosis of psoriatic arthritis was reported by $30(22.6 \%)$ patients with psoriasis. The disease was present in $35 \%$ of men and $25 \%$ of women. Seventeen patients not previously diagnosed were diagnosed using the CASPAR criteria. Therefore, the number of patients with psoriatic arthritis in the study sample was 47 patients, or $35 \%$ of the sample. However, in this study, for the purpose of analyzing the group with psoriatic arthritis, only patients classified by the CASPAR criteria, at the moment of the study, were considered.

Patients with psoriatic arthritis had an average age of $49( \pm 13.2)$ years, the average age of the population without arthritis was $47( \pm 14.4)$ years. No association was found between the groups with and without psoriatic arthritis and previous symptoms of joint, back and neck pain.

There was a great variability in terms of the time between the first skin symptoms and the diagnosis of psoriatic arthritis, which was on average 194 months (16 years) with a median of 174 months (14.5 years), ranging between 08 and 540 months (45). There was no difference between the groups regarding the type of psoriasis and the diagnosis of psoriatic arthritis, chart 2.

It was observed that none of the five patients with psoriasis guttata had a diagnosis of psoriatic arthritis; however, the two patients with nail psoriasis were classified as having psoriatic arthritis.

There was no significant association between lesions on the scalp, nail involvement and the diagnosis of psoriatic arthritis. The patients with arthritis were classified according to the type of involvement in oligoarthritis (three or $10 \%$ of patients), polyarthritis (20 or $67 \%$ of patients) and spondyloarthritis (seven or $23 \%$ of patients).

Patients with psoriatic arthritis had more enthesitis than the group without arthritis (Chart 3). There

Chart 2: Psoriatic arthritis and the type of psoriasis

\begin{tabular}{|llll|}
\hline & \multicolumn{2}{l}{ Psoriatic Arthritis } \\
\cline { 2 - 3 } Type of psoriasis & no & yes & Total \\
\hline Vulgar & 70 & 19 & 89 \\
Guttata & 5 & 0 & 5 \\
Palmoplantar & 4 & 1 & 5 \\
Pustular & 4 & 1 & 5 \\
Erythrodermic & 1 & 1 & 2 \\
Nail psoriasis & 0 & 2 & 2 \\
Total & 84 & 24 & 108 \\
\hline
\end{tabular}


Chart 3: Psoriatic arthritis and enthesitis

\begin{tabular}{|lllll|} 
& & \multicolumn{2}{l|}{ Psoriatic Arthritis } \\
\cline { 3 - 4 } & & no & yes & Total \\
\hline \multirow{2}{*}{ Enthesitis } & No & 96 & 20 & 116 \\
Total & Yes & 07 & 10 & 17 \\
& & 103 & 30 & 133 \\
\hline
\end{tabular}

was no association between the presence of enthesitis and the type of psoriatic arthritis. However no patient with oligoarthritis had enthesitis.

The diagnosis of dactylitis was found in $46.7 \%$ of those diagnosed with psoriatic arthritis and in only $12.6 \%$ of those without a diagnosis of psoriatic arthritis. There was a weak association between the presence of dactylitis and psoriatic arthritis.

Table 1 presents the values of ESR and CRP in the groups.

The values of ESR and CRP were not different between the groups with and without psoriatic arthritis (Mann-Whitney test, $\mathrm{p}>0.05$ ). However there was a tendency to a higher value of CRP in the group with psoriatic arthritis.

In the group of patients with psoriatic arthritis nine patients (30\%) used anti-inflammatory, twelve (40\%) patients used disease-modifying drugs and seven (23.3\%) patients used biological medications.

Table 2 presents the final diagnosis of rheumatic manifestations. It is noteworthy that only $31 \%$ of the patients with psoriasis from the sample had no musculoskeletal manifestation.

\section{DISCUSSION}

It has been difficult to estimate the prevalence of psoriatic arthritis as the results of epidemiological studies have been influenced by several factors: the diagnostic criteria used, the frequency of psoriasis in different geographical areas, the average population age, the case definition and the methodology of the study. ${ }^{9}$

Overall, in studies assessing the prevalence of psoriatic arthritis in patients with psoriasis seen at specific clinics it can vary from $6-42 \% .{ }^{2}$ In studies involving outpatients such as the one by Altobelli et al. ${ }^{13}$ the prevalence rates reached $26 \%$ and in studies with populations that included both individuals and the community hospital environment such as the study by Reich et al. ${ }^{14}$ the prevalence reached $20,6 \%$.

Cross-sectional studies with populations referred to hospital care tend to have a higher prevalence and this is partly explained by a more intense and systematic research to define a case and partly because this group tends to be in the more severe spectrum of the disease. Our study found a high prevalence of psoriatic arthritis (35\%) when we considered the patients who were previously diagnosed and those who met the CASPAR criteria, at the moment of this study. Despite the selection bias, on the other hand, we were careful in trying to make our estimates closer to reality. The study patients had their diagnosis confirmed after clinical evaluation by a dermatologist and a rheumatologist and, as told by Ibrahim et al., such studies often have estimates closer to reality. ${ }^{15}$

Despite the small sample size, statistical significance was achieved in important variables. When compared to the only Brazilian study that evaluates the prevalence of psoriatic arthritis in psoriasis patients our study had the largest number of patients assessed, in addition to being a cross-sectional study. The study of Aslanian et al. was done by retrospective analysis of medical records. ${ }^{16}$

Most of our patients presented with psoriasis vulgar, most commonly associated with psoriatic arthritis, but no difference was seen between the groups regarding the type of psoriasis and the diagnosis of psoriatic arthritis. The time elapsed between the onset of symptoms and the diagnosis of psoriatic arthritis was 16 years, which shows that in our environment the diagnosis of arthritis is usually delayed. ${ }^{2}$

According to a review article the majority of patients $(70 \%)$ developed psoriasis before the joint involvement, which was also observed in our study. ${ }^{9}$ Because the disease tends to present initially in the skin, it is important that the dermatologist identifies the signs of arthritis and then refer the patients to a rheumatologist. We observed that after the evaluation by a rheumatologist, 17 new cases of psoriatic arthritis were detected. This was also demonstrated in the

TABLE 1: Values of ESR and CRP

\begin{tabular}{llllll}
\hline Psoriatic Arthritis & n & Mean & Median & Standard deviation & Standard error \\
\hline VHS & no & 45 & 19,15 & 15,21 & 2,27 \\
$\left(\mathrm{~mm} / \mathbf{1}^{\mathrm{a} h}\right)$ & yes & 27 & 19,89 & 14,14 & 2,72 \\
PCR & no & 33 & 0,96 & 1,52 & 0,27 \\
O & Yes & 26 & 1,90 & 2,24 & 0,45 \\
\hline
\end{tabular}


TABLE 2: Rheumatic diseases

\begin{tabular}{ll}
\hline $\begin{array}{l}\text { Rheumatic diseases associated } \\
\text { with psoriasis }\end{array}$ & N (\%) \\
\hline None & $41(30,8)$ \\
Ostheoartrosis & $12(9,0)$ \\
Myofascial Pain Syndrome & $27(20,3)$ \\
Psoriatic Arthritis & $30(22,6)$ \\
Indefinite & $23(17,3)$ \\
\hline
\end{tabular}

study by TRONTZAS et al. in which rheumatologists had a correct diagnosis in $87.5 \%$ of cases while non rheumatologists only in $7.7 \% .{ }^{17}$ We know that in our country the access to a rheumatologist is often difficult, but recent studies have shown that, fortunately, rheumatologists and dermatologists, when trained, can assess both the skin and the joints with a surprising degree of agreement and accuracy. ${ }^{18}$ Thus, we conclude that the cooperation between these specialties for the early detection of psoriatic arthritis is very important. ${ }^{19}$

Given the difficulty in making the diagnosis, some clinical features should be assessed to predict psoriatic arthritis. Although nail lesions occur more frequently in patients with psoriatic arthritis, this was not observed in our study. In other studies nail lesions were found in all patients with psoriatic arthritis. Despite our results, we consider that the presence of this type of injury suggests the need to investigate joint disease. ${ }^{2}$ In the study by FLORANNE et al. scalp lesions were strongly associated with psoriatic arthritis. Despite the high frequency of patients with lesions in the scalp, there was no such correlation in our study. ${ }^{20}$ More than $30 \%$ of the patients had no information in their protocols on these two variables and that may have influenced the results.

Dactylitis was associated with the presence of psoriatic arthritis, which was expected, since it is also part of the CASPAR criteria. ${ }^{12}$

Although regarded as the primary lesion of psoriatic arthritis, enthesitis was not frequently found in our study and this may be because of the difficulty in the clinical evaluation, since most of the sites of enthesitis are deeply located and further evaluation by ultrasound or MRI is needed to define its presence. ${ }^{9}$

High erythrocyte sedimentation rate and $C$ reactive protein were present in $50 \%$ of cases but only the elevated C-reactive protein was correlated with a higher prevalence of psoriatic arthritis. This can be explained because the erythrocyte sedimentation rate is an indirect measure of inflammatory activity and can be influenced by a variety of factors including the age of the patient and the presence of large amounts of other proteins in the plasma. C-reactive protein is a better index of inflammatory activity. ${ }^{21}$

Many studies have similar results to ours, where the polyarticular form is the most common, but we have to stress that the majority of our patients were not in the early stages of the disease, where the oligoarticular forms are more frequently found. ${ }^{9}$

On the other hand, the Brazilian study by Bonfiglioli et al had different results: $62.7 \%$ had oligoarthritis, and spondyloarthritis was observed in $16.7 \%$ and polyarthritis in $15.7 \%$ of patients, ie, a much lower frequency of polyarthritis. ${ }^{22}$ It should be noted, however, that this study was conducted in the outpatient population referred to rheumatology. This demonstrates that in Brazil more studies are needed to confirm and explain the reasons for these divergent distributions.

Some studies regard having a polyarticular disease as a factor of poor prognosis and this is the most commonly found pattern in our population. ${ }^{23}$ The use of many medications early in the disease is also a factor of poor prognosis. Our patients with psoriatic arthritis, probably due to the fact that they had the polyarticular form, which carries the worst prognosis, and also because they had several comorbidities and illnesses such as diabetes, hypertension, and mechanical joint diseases, often had a high frequency of medication use. ${ }^{23}$

\section{CONCLUSION}

Given the aggressive and debilitating potential of psoriatic arthritis, the need to draw a profile of the clinical, radiological and functional capacity of patients with psoriasis and psoriatic arthritis among us is increasingly important, since we know that results from epidemiological studies are variable and depend on a number of factors leading to limitations in their use and interpretation. In addition, cooperation between rheumatologists and dermatologists for the diagnosis and early institution of therapeutic strategies is important, thus avoiding many complications commonly associated with this disease. 


\section{REFERENCES}

1. Sbd.org [Internet]. Sociedade Brasileira de Dermatologia. Consenso Brasileiro de Psoríase.2009. [acesso 5 Ago 2011]. Disponível em: http://www.sbd.org.br/flash/flash/Arquivos/Pdfs/ConsensoPsor\%C3\%ADase2009.pdf

2. Jamshidi F, Bouzari N, Seirafi H, Farnaghi F, Firooz A. The Prevalence of Psoriatic Arthritis in Psoriatic Patients in Tehran, Iran. Arch Iran Med. 2008;11:162-5.

3. Moghaddassi M, Shahram F, Chams-Davatchi C, Najafizadeh S, Davatchi F. Differentaspectofpsoriaticarthritis: analysisof 150 Iranianpatients. Arch Iran Med. 2009:12:279-83

4. Gladman DD. Psoriatic arthritis from Wright's era until today. J Rheumatol 2009;83:4-8.

5. Setty AR, Choi HK. Psoriatic arthritis epidemiology. Curr Rheumatol Rep. 2007;9:449-54

6. Moll JMH, Wright V. Psoriatic arthritis. Semin Arthritis Rheum. 1973:3,55-78.

7. Gladman DD, Schentag CT, Tom BDM, Chandran V, Brockbank J, Rosen CF, et al. Development and initial validation of a screeningquestionnaire for psoriatic arthritis: The Toronto Psoriatic Arthritis Screen (ToPAS). Ann Rheum Dis. 2009;68:497-501.

8. Leung YY, Tam LS, Ho KW, Lau WM, Li TKY, Zhu TY, et al. Evaluation of the CASPAR criteria for psoriatic arthritis in the Chinese population. Rheumatology (Oxford). 2010;49:112-5.

9. Cantini F, Niccoli L, Nanninil C, Kaloudi O, Bertoni M, Cassara E. Psoriatic arthritis: a systematic review. Int J Rheum Dis. 2010;13:300-17.

10. Feldman SR, Krueger GG. Psoriasis assessment tools in clinical trials. Ann Rheum Dis. 2005;64 Suppl 2:ii65-8.

11. Sieper J, Rudwaleit M, Baraliakos X, Brandt J, Braun J, Burgos-Vargas R, et al. The Assessment of SpondyloArthritisinternational Society (ASAS) handbook: a guide to assess spondyloarthritis. Ann Rheum Dis. 2009;68 Suppl 2:ii1-44.

12. Taylor W, Gladman D, Helliwell P, Marchesoni A, Mease P, Mielants $H$, et al Classification Criteria for Psoriatic Arthritis Development of New Criteria From a Large International Study. Arthritis Rheum. 2006;54:2665-73.

13. Altobelli E, Maccarone M, Petrocelli R, Marziliano C, Giannetti A, Peris K, et al. Analysis of health care and actual needs of patients with psoriasis: a survey on the Italian population. BMC Public Health. 2007;7:59.

14. Reich K, Kruger K, Mossner R, Augustin M. Epidemiology and clinical pattern of psoriatic arthritis in Germany: a prospective interdisciplinary epidemiological study of 1,511 patients with plaque-type psoriasis. Br J Dermatol. 2009;160:1040-7.

15. Ibrahim G, Waxman R, Helliwell PS. The prevalence of psoriatic arthritis in people with psoriasis. Arthritis Rheum. 2009;61:1373-8.

16. Aslanian FM, Lisboa FF, Iwamoto A, Carneiro SC. Clinical and epidemiological evaluation of psoriasis: clinical variants and articular manifestations. J Eur Acad Dermatol Venereol. 2005;19:141-2
17. Trontzas P, Andrianakos A, Miyakis S, Pantelidou K, Vafiadou E, Garantziotou V, et al. Seronegative spondyloarthropathies in Greece: a population-based study of prevalence, clinical pattern, and management. The ESORDIG study. Clin Rheumatol. 2005;24:583-9.

18. Chandran V, Gottlieb A, Cook RJ, Duffin KC, Garg A, Helliwell P, et al. International Multi-centre Psoriasis and psoriatic Arthritis Reability Trial (GRAPPA- IMPART) Assessment of skin, joints, nails and dactylitis. Arthritis Rheum. 2009;61:1235-42.

19. Prey S, Paul C, Bronsard V, Puzenat E, Gourraud PA, Aractingi S, et al. Assessment of risk of psoriatic arthritis in patients with plaque psoriasis: a systematic review of the literature. J Eur Acad Dermatol Venereol. 2010;24 Suppl 2:31-35.

20. Wilson FC, Icen M, Crowson CS, Mcevoy MT, Gabriel SE, Kremers HM. Incidence and clinical predictors of psoriatic arthritis in patients ith psoriasis: a population-based study. Arthritis Rheum. 2009;61:233-9.

21. Gabay C, Kushner L. Acute phase proteins and other systemic responses to inflammation. N Engl J Med. 1999:340:448-54.

22. Bonfiglioli R, Conde RA, Sampaio-Barros PD, Louzada-Junior P, Donadi EA, Bertolo MB. Frequency of HLA-B27 alleles in Brazilian patients with psoriatic arthritis. Clin Rheumatol. 2008;27:709-12.

23. Gladman DD, Antoni C, Mease P, Clegg D0, Nash P. Psoriatic arthritis: epidemiology, clinical features, course, and outcome. Ann Rheum Dis. 2005;64 Suppl 2:ii14-7.

How to cite this article: Carneiro JN, Paula AP, Martins GA. Psoriatic arthritis in patients with psoriasis: evaluation of clinical and epidemiological features in 133 patients followed at the University Hospital of Brasília. An Bras Dermatol. 2012;87(4):539-44. 